\title{
Demand response of space heating using model predictive control in an educational office building
}

\author{
Aleksi Mäki ${ }^{1, *}$, Juha Jokisalo ${ }^{2}$, and Risto Kosonen ${ }^{2,3}$ \\ ${ }^{1}$ Oy Granlund Consulting, Helsinki, Finland \\ ${ }^{2}$ Aalto University, Department of Mechanical Engineering, Espoo, Finland \\ ${ }^{3}$ College of Urban Construction, Nanjing Tech University, China
}

\begin{abstract}
The building sector plays a remarkable role in decreasing of the overall global $\mathrm{CO}_{2}$ emissions since as much as $30 \%$ from the total global $\mathrm{CO}_{2}$ emission are generated in buildings. Demand response provides one possibility to tackle the problem. It can be used to decrease $\mathrm{CO}_{2}$ emissions in entire energy system in addition to providing energy cost savings for building owners and energy companies. In this study, the demand response potential was estimated in an educational office building that was heated by district heating. The potential was defined in respect of energy cost savings, energy flexibility and thermal comfort. Model predictive control was developed, which utilized the dynamic hourly district heating prices. The MPC algorithm written in the Matlab software, predicted the future heating demand while the optimization algorithm NSGA-II minimized the heating energy cost, maximized the energy flexibility and maintained acceptable thermal comfort by changing the space heating temperature setpoints. The operation of the MPC algorithm was tested in the IDA ICE 4.8 simulation software. As a result, the annual district heating energy costs could be reduced by $4.2 \%$ compared to the reference case with constant space heating temperature setpoint of $21^{\circ} \mathrm{C}$. The maximum flexibility factor attained was $14 \%$. Acceptable level of thermal comfort was maintained throughout the simulation time.
\end{abstract}

\section{Introduction}

Demand response constructs a group of methods where the end-user's energy load is modified to decrease the aggregated overall $\mathrm{CO}_{2}$ emissions of the energy production and to enhance the efficiency of the whole energy system. The end-users load may be shifted from expensive peak load periods to cheaper off-peak periods, the peak load may be cut, or extra load may be induced to off-peak periods. As a result, the aggregated load in the energy system will stabilize and the demand for the fossilfuel intensive peak-power plants will decrease.

There exists two type of pricing models in demand response: price-based and intensive-based models. This study focused in the price-based model where the building's load was modified according to the dynamic district heating price.

From the building owner's point of view, the objective in demand response is to decrease the annual energy costs by maintaining indoor environmental quality that supports the building's usage. Several studies have shown that the decreased level of IEQ decreases the occupant's productivity [1-2] and it may also cause health hazards [3] which both would cancel out the attained energy cost savings. Therefore, the DR should be controlled so that the IEQ would always be maintained at acceptable level.

The objective of this study was to define the potential of DR in an educational office building in the perspective of energy cost savings, energy flexibility and thermal comfort. The flexibility factor introduced by Le Dreau and Heiselberg [4] was used to depict how well the
DR shifts the load from expensive periods to cheaper energy cost periods.

Earlier demand response studies have predominantly dealt with the electricity loads while the DR of district heating has been studied much less. For this reason, in this study the DR of district heating is examined by modifying the space heating load in the studied case building. The space heating was chosen as the modified load because the study by Martin [5] showed that it possesses the greatest potential among the building's HVAC heating loads.

\section{Methodology}

\subsection{MPC algorithm}

A model predictive algorithm (MPC) was developed in this study to implement the DR of space heating. The process chart in Figure 1 presents the idea of DR with the MPC algorithm.

\footnotetext{
* Corresponding author: aleksi.maki@granlund.fi
} 


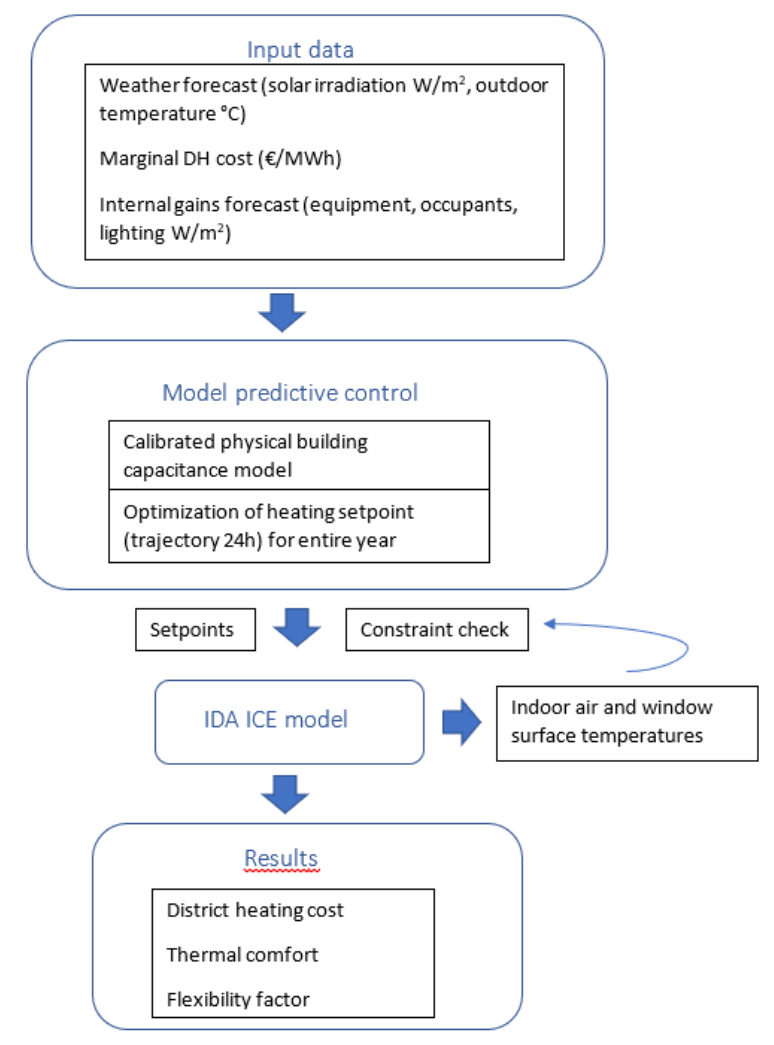

Fig. 1. Process chart of the MPC algorithm.

First the input data including the weather forecast, dynamic district heating price and internal gain forecast was imported to the MPC algorithm. The MPC algorithm written in Matlab composed of the calibrated physical building model and an optimization algorithm. The optimization algorithm used the physical building model in finding the most optimal space heating temperature setpoints over the predicted time spam of either 12 or 24 hours. The optimal setpoints were then exported to IDA ICE simulation software where the efficiency of the MPC algorithm was tested.

In addition, a decentralized feedback control was added to IDA to prevent overheating of spaces. The feedback control replaced the optimized space heating setpoint by the normal setpoint of $21^{\circ} \mathrm{C}$ if the room air temperature in any room exceeded $24^{\circ} \mathrm{C}$.

The MPC algorithm was run throughout the year to get the annual space heating temperature setpoints. Therefore, the final simulation results depict the annual DR potential in respect of district heating costs, thermal comfort level and energy flexibility.

\subsection{Case building}

The case building Otakaari 4, an educational office building constructed in 1960s, located in the Aalto University campus area in Espoo, Finland. This building was chosen because it resembles typical office building in Finland of that era in respect of structures and HVAC technology. The building provided facilities for the University faculty and students: lecture rooms, offices, student restaurant and alleys. However, in this study only the $4^{\text {th }}$ floor of the office wing of the building was investigated. Layout of the $4^{\text {th }}$ floor is shown in Figure 2. The case floor had heated net floor area of $586 \mathrm{~m}^{2}$ and envelope area of $947 \mathrm{~m}^{2}$.

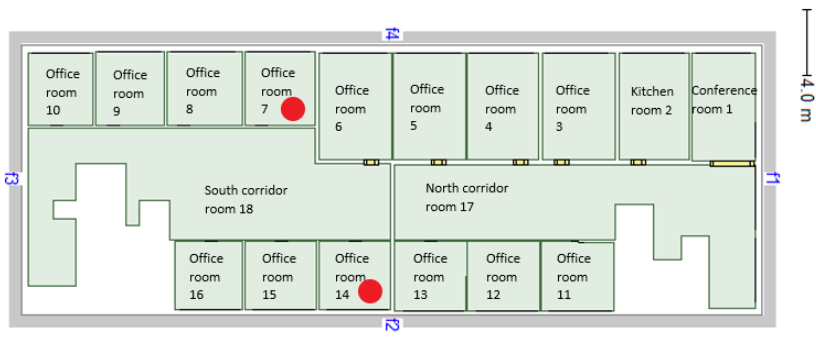

Fig. 2. Layout of the case floor.

The building envelope and all the bearing structures were built of reinforced concrete which resulted in relatively high building mass heat capacity. With the moderate insulation level, this building offered great possibilities for DR implementation [4]. In the latest renovation, the windows were renewed, and the ventilation system was also renovated. Table 1 presents the building structure properties and the average ventilation air flow rate.

Tab. 1. Properties of the case building.

\begin{tabular}{|l|l|l|}
\hline Structures & $\begin{array}{l}\mathrm{U} \text {-value } \\
\left(\mathrm{W} / \mathrm{m}^{2}, \mathrm{~K}\right)\end{array}$ & $\mathrm{g}$-value \\
\hline External wall & 0.38 & \\
\hline Roof & 0.3 & \\
\hline Window, South-West & 1.1 & 0.38 \\
\hline Window, North-West and North-East & 1.1 & 0.59 \\
\hline Window frames, All & 2.0 & \\
\hline Air thightness & $\mathrm{ACH}$ & \\
\hline 4th floor & 1.6 & \\
\hline Ventilation & $\mathrm{qv}\left(\mathrm{l} / \mathrm{s}, \mathrm{m}^{2}\right)$ & Schedule \\
\hline 4th floor average & 2 & $24 / 7$ \\
\hline
\end{tabular}

The space heating was supplied by hydronic radiators manufactured by Purmo. Space heating, AHU heating and the DWH were all heated by the district heating. One chiller offered space cooling in one corridor of the case floor, but it was neglected since the DR potential of space heating was studied. The internal gains were evaluated based on the number of work stations in each office room. Occupancy rate of $40 \%$ was assumed. The internal gains and the schedules are shown in Table 2. 
Tab. 2. Internal gains and schedules.

\begin{tabular}{|l|l|l|l|}
\hline $\begin{array}{l}\text { Internal heat } \\
\text { gain }\end{array}$ & \multicolumn{2}{|l|}{ Value } & $\begin{array}{l}\text { Schedule } \\
\text { hours }\end{array}$ \\
\hline Lighting & $7.5 \mathrm{~W} / \mathrm{m}^{2}$ & $08-16$ \\
\hline Equipment & $50 \mathrm{~W} /$ occupant & $08-16$ \\
\hline Occupancy & $100 \%$ & $40 \%$ & \\
\hline $\begin{array}{l}\text { Total number } \\
\text { of occupants }\end{array}$ & 40 & 16 & $08-16$ \\
\hline
\end{tabular}

\subsection{Calibrated building capacity model}

Simple two capacity RC-model was used to predict the heating demand in the MPC algorithm (Figure 3). The two-capacity RC-model composes of two temperature node points, first one placed in the room air and the another one in the lumped building mass point. The heat transfer is described by the conductances and the heat gains from occupants, solar, equipment, lighting and space heating units. The heating demand to reach specific indoor air temperature setpoint could be solved from the heat balance equations for both air and mass node points.

Two rooms from the studied floor were modelled in the RC-model to get solar radiation values from the opposite facades of the building (marked in Figure 2). The modelling was limited to two rooms since the modelling of numerous rooms would have taken more time without giving remarkable benefits in the accuracy of the endresults of the DR potential. The conductances and capacitances were defined by calibrating the RC-model against the more sophisticated and validated IDA ICE room model. The static and dynamic calibration steps resulted in well-performing and accurate RC-model as can be seen from Figure 4. The air temperature in the RCmodel matched accurately with the one in IDA ICE model. The calibrated parameters are shown in Table 3.

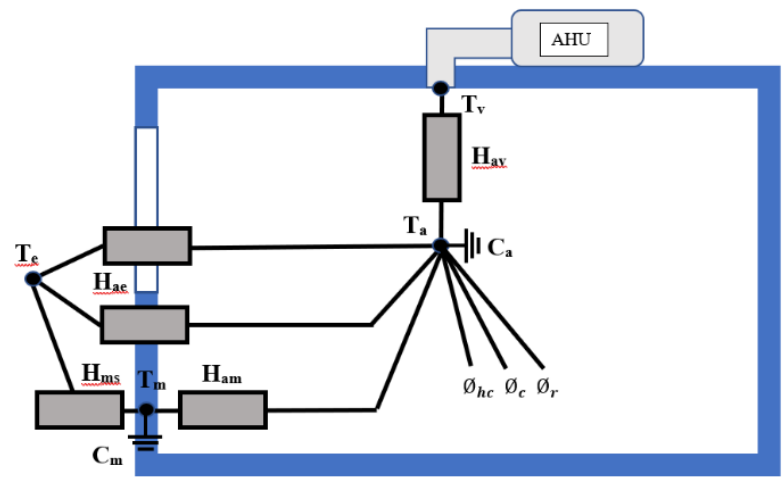

Fig. 3. Schematic of the two capacity RC-model. Symbols are defined in table below.

\begin{tabular}{|l|l|l|}
\hline Symbol & Description & Unit \\
\hline $\mathbf{C}_{\mathbf{m}}$ & Heat capacitance of the mass node point & $\mathrm{J} / \mathrm{K}$ \\
\hline $\mathbf{C}_{\mathbf{a}}$ & $\begin{array}{l}\text { Heat capacitance of the air node point } \\
\text { Combined conductance of the windows } \\
\text { and leakage air }\end{array}$ & $\mathrm{J} / \mathrm{K} / \mathrm{K}$ \\
\hline $\mathbf{H}_{\mathbf{a e}}$ & \\
\hline
\end{tabular}

\begin{tabular}{|c|c|c|}
\hline $\mathbf{H}_{\mathrm{ms}}$ & $\begin{array}{l}\text { Conductance between mass node and } \\
\text { outdoor air node point }\end{array}$ & $\mathrm{W} / \mathrm{K}$ \\
\hline $\mathbf{H}_{\mathrm{am}}$ & $\begin{array}{l}\text { Conductance between mass node and } \\
\text { indoor air node point }\end{array}$ & $\mathrm{W} / \mathrm{K}$ \\
\hline $\mathbf{H}_{\mathrm{av}}$ & Heat capacity flow through ventilation & $\mathrm{W} / \mathrm{K}$ \\
\hline $\mathbf{T}_{\mathbf{e}}$ & Exterior/outdoor temperature & $\begin{array}{l}{ }^{\circ} \mathrm{C} \\
\text { or } \mathrm{K}\end{array}$ \\
\hline $\mathbf{T}_{\mathbf{m}}$ & Mass temperature node point & $\begin{array}{l}{ }^{\circ} \mathrm{C} \\
\text { or K }\end{array}$ \\
\hline $\mathbf{T}_{\mathbf{a}}$ & Air temperature node point & $\begin{array}{l}{ }^{\circ} \mathrm{C} \\
\text { or } \mathrm{K}\end{array}$ \\
\hline $\mathbf{T}_{\mathbf{v}}$ & Supply air temperature node point & $\begin{array}{l}{ }^{\circ} \mathrm{C} \\
\text { or } \mathrm{K}\end{array}$ \\
\hline$\emptyset_{h c}$ & Zone heating/(cooling) power & W \\
\hline$\emptyset_{c}$ & Convective heat loads & W \\
\hline$\emptyset_{r}$ & Radiative heat loads & W \\
\hline
\end{tabular}

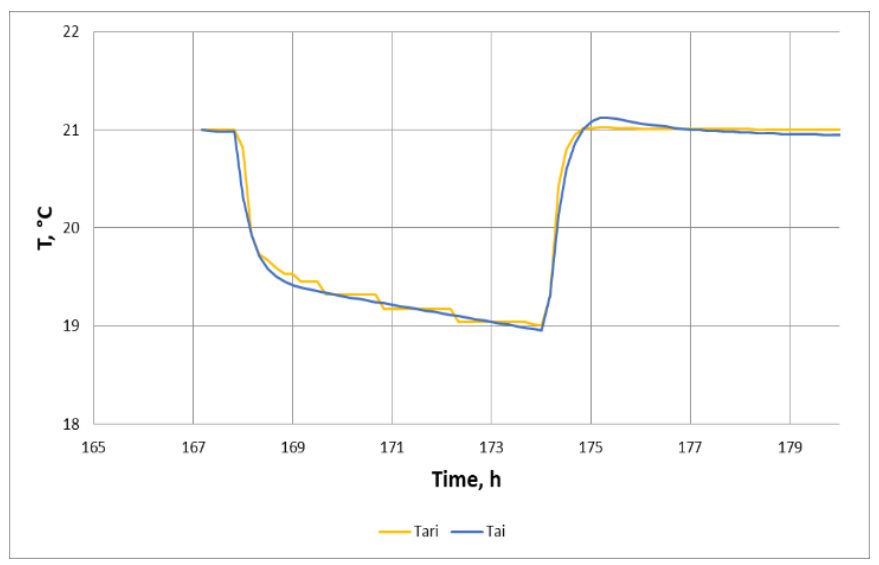

Fig. 4. Indoor air temperature in the calibrated RC-model (Tai) and IDA ICE calibration reference model (Tari).

Tab. 3. RC-model parameters after calibration.

\begin{tabular}{|c|c|c|c|c|c|c|}
\hline $\mathbf{H}_{\text {ams }}$ & $\mathbf{H}_{\mathrm{av}}$ & $\mathbf{H}_{\mathbf{a e}}$ & $\mathbf{H}_{\mathrm{ms}}$ & $\mathbf{H}_{\mathbf{a m}}$ & $\mathbf{C}_{\mathbf{a}}$ & $\mathbf{C}_{\mathbf{m}}$ \\
\hline $\mathrm{W} / \mathrm{K}$ & $\mathrm{W} / \mathrm{K}$ & $\mathrm{W} / \mathrm{K}$ & $\mathrm{W} / \mathrm{K}$ & $\mathrm{W} / \mathrm{K}$ & $\mathrm{kJ} / \mathrm{K}$ & $\mathrm{kJ} / \mathrm{K}$ \\
\hline 10.4 & 51.8 & 7.7 & 10.7 & 372.2 & 336.3 & 19290 \\
\hline
\end{tabular}

\subsection{Optimization}

Model predictive control algorithm involved an NSGA II optimization algorithm which was used to find out the optimal space heating setpoint trajectories for the upcoming hours. The NSGA-II algorithm was chosen because it belongs to genetic algorithms which can find multiple solutions with one optimization round making the optimization efficient compared to preference-based optimization methods [6]. The original optimization code was developed by Tutum [7].

Optimization dealt with three optimization functions. Optimization tried to minimize the total heating energy cost (F1), reach the maximum heating energy flexibility (F2) and to minimize the thermal discomfort described by the deviation of the air temperature of the $\mathrm{RC}$-model to the preferred air temperature set according to the Finnish indoor air classification level S2 (F3) [8]. 


$$
\begin{aligned}
& \operatorname{Min}\left\{F 1(\boldsymbol{x})=\sum_{t=1}^{n} \text { heating power }(\boldsymbol{x}(t)) * \text { DH price }(t)\right\} \\
& \operatorname{Max}\{F 2(\boldsymbol{x}(t))=\text { flexibility factor }\} \\
& \operatorname{Min}\left\{F 3(\boldsymbol{x})=\sum_{t=1}^{n}\left(T_{a}(\boldsymbol{x}(t))-T_{\text {ref }}(\boldsymbol{x}(t))\right)^{2}\right\}
\end{aligned}
$$

where

$$
\begin{array}{ll}
\boldsymbol{x} & \text { space heating temperature setpoints } \\
t & \text { time instance } \\
n & \text { length of the prediction horizon } \\
T_{a} & \text { air temperature } \\
T_{r e f} & \text { reference air temperature. }
\end{array}
$$

The optimization variable $(\boldsymbol{x})$ was restricted to get values between [20-24.5] ${ }^{\circ} \mathrm{C}$ to maintain acceptable thermal comfort level. During the summertime when the $24 \mathrm{~h}$ average outdoor air temperature exceeded $0{ }^{\circ} \mathrm{C}$ the acceptable range was changed to $[20-21]^{\circ} \mathrm{C}$ preventing overheating. The length of the predicted heating demand (n) was set to either 12 or $24 \mathrm{~h}$, which also defined the length of the optimization variable vector $\boldsymbol{x}$.

In addition to specifying the acceptable range for the space heating setpoints, the optimization had one constraint for the heating power. The heating power was not allowed to exceed the maximum outdoor air dependant heating power (physical restriction).

\subsection{Input data}

The input data involved the weather/climate data and the dynamic DH prices. The TRY weather data was chosen since it resembles average annual weather in the Finnish climate. Thus, also the results of this study resemble the DR potential in the average weather conditions [9]. The DH marginal cost data utilized in this study was generated by Rinne [10]. The cost data was generated using the same weather data which is mandatory since the DH costs are weather dependent.

\subsection{Simulated cases}

The studied simulation cases composed of Reference cases $\mathrm{R}$, optimization cases $\mathrm{O}$ and the parameter analysis cases $\mathrm{C}$. The cases are shown in Table 4.

The reference cases (without DR) formed a benchmark for which the DR cases could be compared. The temperature setpoint was constant throughout the year, either $21{ }^{\circ} \mathrm{C}(\mathrm{R} 1)$, which is a normal temperature target value in Finnish building code or $20^{\circ} \mathrm{C}$ (R2) which

\begin{tabular}{|c|c|c|c|}
\hline Case & $\begin{array}{l}\text { Optimization } \\
\text { objectives }\end{array}$ & $\begin{array}{l}\text { Prediction } \\
\text { horizon, [h] }\end{array}$ & $\begin{array}{c}\text { Temperature } \\
\text { setpoint range, }\left[{ }^{\circ} \mathrm{C}\right]\end{array}$ \\
\hline $\mathrm{R} 1$ & - & - & Cons. 21 \\
\hline R2 & - & - & Cons. 20 \\
\hline $\mathrm{O} 1.2$ & MIN(F1) & 12 & [20-23] \\
\hline $\mathrm{O} 2.2$ & MAX(F2) & 12 & [20-23] \\
\hline $\mathrm{O} 3.2$ & $\begin{array}{l}\text { MIN(F1) } \\
\text { MIN(F3) }\end{array}$ & 12 & [20-23] \\
\hline $\mathrm{O} 4.2$ & $\begin{array}{l}\text { MAX(F2) } \\
\text { MIN (F3) }\end{array}$ & 12 & [20-23] \\
\hline $\mathrm{O} 2.3$ & MAX(F2) & 24 & [20-23] \\
\hline $\mathrm{O} 3.3$ & $\begin{array}{l}\text { MIN(F1) } \\
\text { MIN(F3) }\end{array}$ & 24 & [20-23] \\
\hline $\mathrm{O} 4.3$ & $\begin{array}{l}\operatorname{MAX}(F 2) \\
\operatorname{MIN}(F 3)\end{array}$ & 24 & [20-23] \\
\hline $\mathrm{C} 1.2$ & $\begin{array}{l}\text { MAX(F2) } \\
\text { MIN (F3) }\end{array}$ & 24 & {$[20-24.5]$} \\
\hline $\mathrm{C} 2.2$ & $\begin{array}{l}\text { MAX(F2) } \\
\text { MIN (F3) }\end{array}$ & 24 & [20-21] \\
\hline
\end{tabular}
resembles a case where the heat is conserved. In the optimization cases the objective functions and the length of the prediction horizon was changed. In the parameter analysis different temperature setpoint ranges were studied.

Tab. 4. Studied simulation cases $(\mathrm{R}=$ reference cases, $\mathrm{O}=$ optimization cases, $\mathrm{C}=$ parameter analysis cases $)$.

\section{Results}

The results from the MPC algorithm implemented DR cases are analysed in respect of energy cost savings, energy flexibility and thermal comfort. The annual heating costs and flexibility factors are presented in Table 5. Heating energy consumption and costs are given per heated net floor area allocated form and the relative savings are calculated in reference to case R1.

The results show that the highest energy cost savings were obtained from the DR case O1.2. However, the cases O3.3 and C2.2 reached almost the same cost savings. The cost savings in these DR cases are close to the savings given by heat conservation in the reference case R2.

The highest flexibility factor of $14 \%$ was reached in the cases $\mathrm{O} 4.3, \mathrm{C} 1$ and $\mathrm{C} 2$ which all had flexibility factor as one objective. The flexibility was increased considerably compared to the reference cases R1 and R2 which had FF of roughly $7 \%$.

The cost optimized cases and the flexibility optimized cases differed in the strategy they used to modify the buildings heating load. The cases having cost optimization as one objective tried to decrease the energy costs by decreasing the heating consumption similarly to reference case R2. In comparison, the cases having flexibility optimization as one objective, utilized the load shifting strategy where the load was shifted from expensive periods to cheaper energy cost periods. The 
difference between these strategies can be seen from the cost and energy saving ratios shown in table 5 and from the Figure 5 where the heating energy cost is divided according to district heating price ranges.

Tab. 5. Simulation results.

\begin{tabular}{|c|c|c|c|c|c|c|}
\hline CASE & $\begin{array}{c}\text { DH } \\
\text { energy }\end{array}$ & Cost & $\begin{array}{c}\text { DH } \\
\text { energy }\end{array}$ & Cost & $\begin{array}{c}\text { Cost } \\
\text { and } \\
\text { energ } \\
\text { y } \\
\text { saving } \\
\text { ratio }\end{array}$ & $\begin{array}{c}\text { Flexibility } \\
\text { factor }\end{array}$ \\
\hline & $\mathrm{kWh} / \mathrm{m}^{2}$ & $\mathbf{E} / \mathrm{m}^{2}$ & $\%$ & $\%$ & - & $\%$ \\
\hline $\mathbf{R 1}$ & 128.3 & 8.2 & 0.0 & 0.0 & 0.0 & 7 \\
\hline $\mathbf{R 2}$ & 121.2 & 7.8 & -5.5 & -4.8 & 0.9 & 7 \\
\hline $\mathbf{0 1 . 2}$ & 121.4 & 7.8 & -5.4 & -4.7 & 0.9 & 7 \\
\hline $\mathbf{0 2 . 2}$ & 125.3 & 7.9 & -2.3 & -3.1 & 1.3 & 10 \\
\hline $\mathbf{0 3 . 2}$ & 122.3 & 7.8 & -4.7 & -4.2 & 0.9 & 6 \\
\hline $\mathbf{0 4 . 2}$ & 126.2 & 8.0 & -1.6 & -2.7 & 1.6 & 11 \\
\hline $\mathbf{0 2 . 3}$ & 125.7 & 7.9 & -2.0 & -4.0 & 2.0 & 13 \\
\hline $\mathbf{0 3 . 3}$ & 122.5 & 7.8 & -4.5 & -4.6 & 1.0 & 7 \\
\hline $\mathbf{0 4 . 3}$ & 127 & 7.9 & -1.0 & -3.0 & 2.9 & 14 \\
\hline $\mathbf{C 1 . 2}$ & 127.2 & 8.0 & -0.9 & -2.5 & 3.0 & 13 \\
\hline $\mathbf{C 2 . 2}$ & 126 & 7.8 & -1.8 & -4.3 & 2.4 & 14 \\
\hline
\end{tabular}

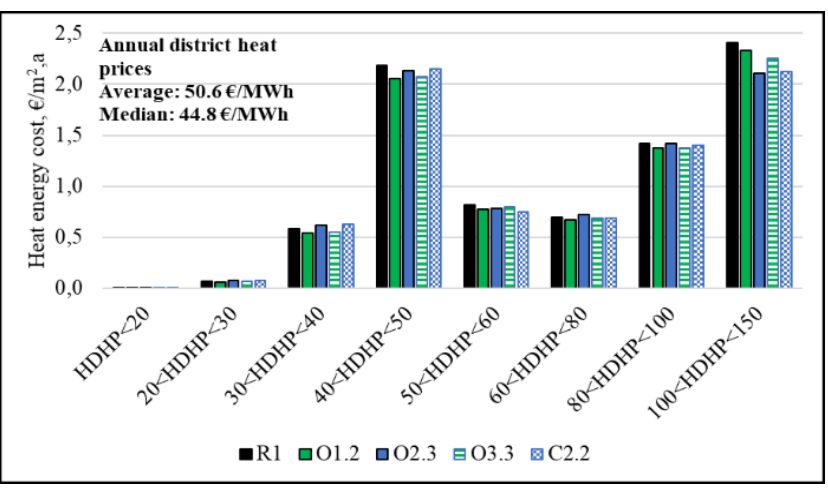

Fig. 5. Heating energy cost divided to district heating price ranges.

The cases where the thermal comfort acted as one objective resulted in slightly lower heating cost savings compared to cases optimized only by costs or FF. The length of time for which the heating demand was predicted (length of the prediction horizon) had a significant effect on the given results. The longer prediction time increased the cost savings and decreased the heating energy savings in both cost and flexibility optimized cases.

The parameter analysis cases ( $\mathrm{C}$ cases) revealed that the heat loading seems not to be feasible in this case building. In the case $\mathrm{C} 1.2$ the allowed temperature setpoint range was $\left[20-24.5{ }^{\circ} \mathrm{C}\right.$ while it was [20-21] ${ }^{\circ} \mathrm{C}$ in case $\mathrm{C} 2.2$. The case $\mathrm{C} 2.2$ resulted in higher heating cost savings and therefore the heat loading with temperature setpoint above $21^{\circ} \mathrm{C}$ seems not to be feasible. The reason for this might be that the relatively high ventilation air flows would flush the heat away before it could be loaded to the building mass. Thermal comfort level in the simulation cases was analysed by plotting the air temperature duration curves of the coldest room in the case floor. The duration curves showing cases R1, R2, $\mathrm{O} 1.2, \mathrm{O} 2,2, \mathrm{O} 3.2$ and $\mathrm{O} 4.2$ are presented in Figure 6. The temperature duration curves show that the air temperature did not drop below $20{ }^{\circ} \mathrm{C}$ in any of the simulated cases. As the $20{ }^{\circ} \mathrm{C}$ is regarded as the minimum allowed air temperature in the Finnish indoor air classification [8], it can be concluded that the acceptable thermal comfort was maintained in all of the cases.

In addition, Figure 6 shows that the FF optimized cases resulted in higher room air temperature than the cost optimized cases. Thermal comfort level in these cases were also higher (according to tempearture targets in [8]). The cases where the thermal comfort was also optimized resulted in slightly higher room air temperatures and comfort levels. The difference was small because the decision between two optimization objectives (either cost + comfort or FF + comfort) was always done so that either cost or FF was preferred over the comfort.

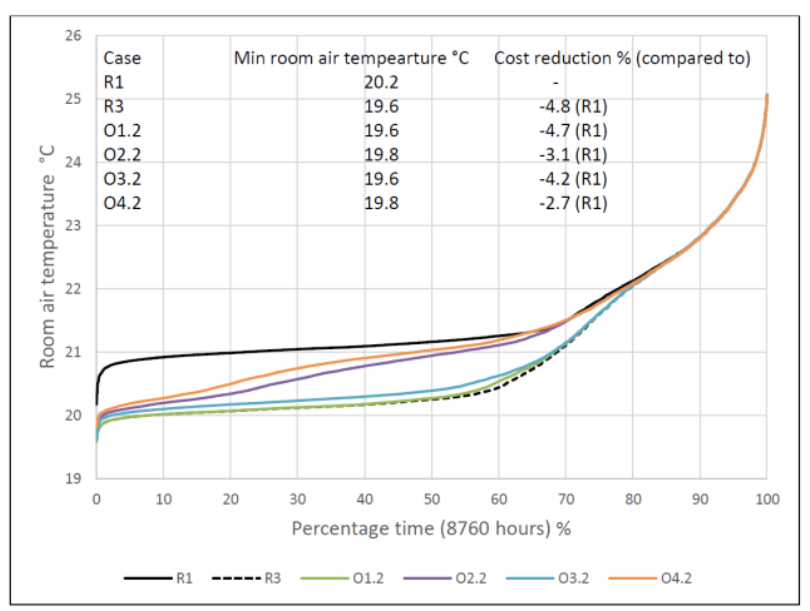

Fig. 6. Duration curves of the coldest room of the case floor.

\section{Discussion}

The reliability of the results depended mostly on the accuracy of the modelling and the accuracy of the input data. The relatively small heating cost savings ( $5 \%)$ obtained with the MPC algorithm may be due to number of reasons. One possibility to low cost savings is that the relatively high ventilation air flow rates prevented the heat loading into the structures and thus the load shifting potential was restricted. In other hand the results are significantly dependent of the used dynamic $\mathrm{DH}$ price model. In addition, the developed MPC algorithm should be tested in different buildings having different structural properties and usage. All in all, the obtained results are in close agreement with the results from the earlier DR study in the same building by Martin [5]. 


\section{Conclusions}

The MPC algorithm developed in this study was used to implement demand response of space heating in an educational office building in Finland. It succeeded in decreasing the heating energy costs by $5 \%$, improving the energy flexibility from $7 \%$ to $14 \%$ and maintaining acceptable thermal comfort throughout the simulation time.

The different combinations of optimization objectives showed that when the heating energy costs were minimized as one objective, the MPC algorithm ended up to conserve heating load. If the energy flexibility acted as one objective the algorithm ended up using the load shifting DR strategy.

The parameter analysis performed, revealed that heat loading with space heating setpoints above $21^{\circ} \mathrm{C}$ was not economically feasible. This may be due to relatively high ventilation air flow rates in the case building.

This study was part of REINO research project that investigated intelligent control strategies in the sustainable building energy systems. Authors would like to thank Business Finland for funding the study and Granlund Consulting Oy for supporting with writing of this conference paper.

\section{References}

1. O. Seppänen, F. Wisk and Q.H. Lei. "Effect of temperature on task performance in office environment", Lawrence Berkeley National Laboratory, (2006).

2. P. Wargocki and D.P. Wyon. "Ten questions concerning thermal and indoor air quality effects on the performance of office work and schoolwork", Building and Environment, Vol. 112, pp. 359-366, (2017).

3. World Health Organization. "Indoor environment: health aspects of air quality, thermal environment, light and noise", (1990).

4. J. L. Dreáu \& P. Heiselberg. "Energy flexibility of residential buildings using short term heat storage in the thermal mass", Energy, Vol. 111, pp. 991-1002, (2016).

5. K. Martin. "Demand response of heating and ventilation within educational office buildings", Master's Thesis, Aalto University, Espoo, pp. 124, (2017).

6. K. Deb. "Multi objective optimization using evolutionary algorithms", John Wiley and Sons, UK, pp. 515, (2008).

7. C.C. Tutum. "Optimization of thermo-mechanical conditions in friction stir welding", Doctoral Dissertation, (DTU), Copenhagen, 2010, pp. 159.

8. FiSIAQ. "Finnish indoor climate classification", Helsinki, pp. 22, (2008).

9. T. Kalamees, K. Jylhä, H. Tietäväinen, J. Jokisalo, S. Ilomets, R. Hyvönen, and S. Saku. 'Development of weighting factors for climate variables for selecting the energy reference year according to the EN ISO 15927-4 standard", Energy and Buildings, Vol. 47, pp. 53-60, (2012).
10. S. Salo et al. "The Impact of Optimal Demand Response Control and Thermal Energy Storage on a District Heating System", accepted for publication in Energies-journal. 